\title{
Diffuse lymphangiomatosis: Are there any clinical or therapeutic standards?
}

\author{
Charalambos Zisis, MD, PhD, FETCS, ${ }^{a}$ Konstantinos Spiliotopoulos, MD, ${ }^{a}$ Marios Patronis, MD, ${ }^{a}$ George Filippakis, MD, \\ Grigoris Stratakos, MD, PhD, ${ }^{\mathrm{b}}$ George Tzelepis, MD, PhD, ${ }^{\mathrm{c}}$ and Ion Bellenis, MD, PhD, FETCS, ${ }^{a}$ Athens, Greece
}

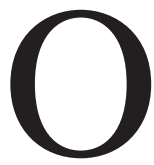

ne of a variety of clinical disorders representing congenital developmental malformations of the lymphatic system, lymphangiomatosis describes the presence of multiple lymphangiomas. It is associated with other lymphatic abnormalities, and $75 \%$ of cases involve multiple organs. It most commonly presents in childhood, with predilection for thoracic and neck lesions, with up to $75 \%$ of patients having bony involvement. ${ }^{1}$

\section{Clinical Summary}

A 23-year-old man was referred to our department for a large left-sided pleural effusion representing a chylothorax as demonstrated after thoracocentesis. He had had persistent cough for months without dyspnea or hemoptysis. His medical history included small bowel resection at the age of 6 years for acute intestinal obstruction owing to intestinal lymphangiomatosis. The computed tomographic scan revealed diffuse abnormal mediastinal, retrocrural, and peritoneal lymphatic tissue with enlarged, nonhomogeneous spleen (Figure 1).

A drain was initially inserted in the left side of the chest and drained $2500 \mathrm{~mL}$ of chylous effusion. This was followed by conservative management with nothing by mouth and total parenteral nutrition support for 2 weeks. The amount of draining fluid, however, did not fall to less than $500 \mathrm{~mL}$ per day, and a new computed tomographic scan after 12 days revealed a trapped left lung with pleural space loculations (Figure 2); thus, a decision was made to proceed with surgical intervention. Lymphatic cystic spaces developed in all mediastinal, diaphragmatic, parietal, and visceral pleurae. Pleural surfaces were fibrous in some positions and watery in others, with milky fluid flowing throughout. Decortication with parietal, visceral, and diaphragmatic pleurectomy was performed through a left posterolateral thoracotomy. Fibrin glue was applied along the posterior mediastinal pleura. Total excision of the lesion was impossible owing to its diffuse character and "fluid" substance, preventing the separation of pathologic from normal structures. The postoperative course was uneventful, drainage stopped after the third postoperative day, a normal diet was established, the chest tube was removed on the sixth postoperative

From the Department of Thoracic and Vascular Surgery, ${ }^{\text {a Evangelismos }}$ Hospital, and the Departments of Intensive Care and Chest Diseases ${ }^{\mathrm{b}}$ and Pathophysiology, ${ }^{\mathrm{c}}$ Medical School, University of Athens, Athens, Greece.

Received for publication Dec 24, 2006; accepted for publication Feb 7, 2007.

Address for reprints: Charalambos Zisis, MD, PhD, FETCS, 17a, Patriarchou Grigoriou str, 166 74-Glyfada, Athens, Greece (E-mail: chzisis@ hol.gr2).

J Thorac Cardiovasc Surg 2007; 133:1664-5

$0022-5223 / \$ 32.00$

Copyright @ 2007 by The American Association for Thoracic Surgery doi:10.1016/j.jtcvs.2007.02.005 day, and the patient was discharged 2 days later. The patient is doing well with no symptoms 6 months later.

\section{Discussion}

This patient's presentation is unusual and unique compared with that of other patients with lymphangiomatosis because of its controversial nature: on the one hand there is the duration of the disease, starting as acute intestinal obstruction requiring intestinal resection when the patient was 6 years old; on the other hand there is the benign course, as the second clinical manifestation occurred 17 years later with the patient remaining asymptomatic in the interim! The involvement of both the retroperitoneal space and the mediastinal compartments in a diffuse pattern is rare and suggests advanced disease with organ involvement. Paradoxically, in the case reported, the spleen is affected, whereas the bones and the lungs are not involved. Chylous pleural effusion and chylopericardium have been reported as manifestations of lymphangiomatosis in younger patients (early or late childhood), having been attributed to bone lymphangiomas resulting in progressive lysis of the bones and replacement with fibrous strands (Gorham's disease). ${ }^{2}$ In contrast, the patient profile in the case presented is different, and the chylothorax originates in pleural involvement.

The involvement of serosal surfaces and viscera has been described in the past as the most significant adverse prognostic factor in lymphangiomatosis. ${ }^{3}$ Although the disease is usually located in one part of the mediastinum (with a slightly greater prevalence in the anterior part), ${ }^{3}$ in our case all compartments are affected.

Pathophysiologic changes resulting in chylous pericardial or pleural effusions are not sufficiently known. The onset of this complication does not seem to depend on the pathologic "burden" of the disease, the extent of involved tissue, and organs or the age

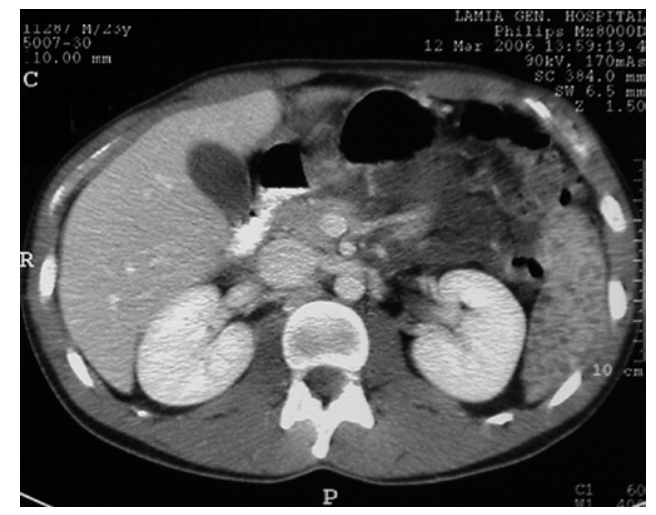

Figure 1. Peritoneal lymphangiomatosis with enlarged, patchy affected spleen. 


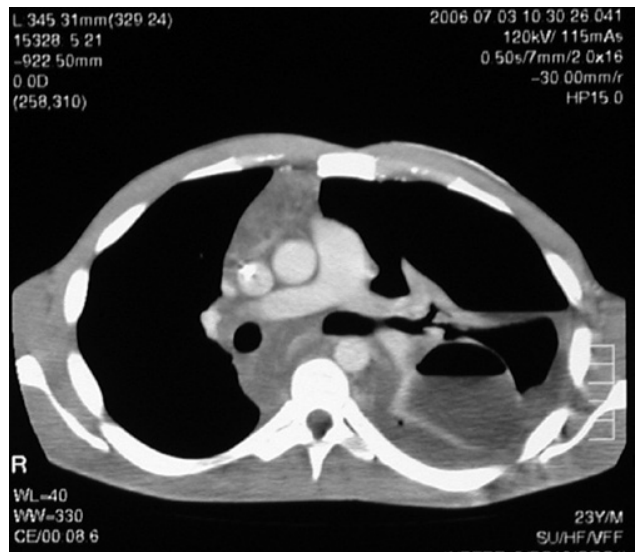

Figure 2. Mediastinal involvement and loculated cystic spaces of the left pleural cavity.

of the patient. Therefore, treatment cannot be standardized and decision-making is customized to the particularities of the case. ${ }^{4}$

Generalized lymphangiomatosis management can be challenging. Surgical treatment is indicated for complications (such as chylopericardium and chylothorax) or for biopsy. An important issue for management of chylous effusions is that there is not one specific source of chyle that can be stopped through the thoracic duct ligation; instead, there is a wide abnormal network of lymphatic channels. However, the best results have been reported with pleurectomy, with or without thoracic duct ligation, whereas thoracic duct ligation alone was unsuccessful in all cases. Fibrin glue application may help control lymphatic leakage from exposed surfaces after pleurectomy. ${ }^{2}$ Other treatment options include interferon alfa and systemic chemotherapy with limited success, and radiation in fractioned dose has been promising for patients with extensive mediastinal disease. ${ }^{5}$

\section{References}

1. Faul JL, Berry GJ, Colby TV, Ruoss SJ, Walter MB, Rosen GD, et al. Thoracic lymphangiomas, lymphangiectasis, lymphangiomatosis, and lymphatic dysplasia syndrome. Am J Respir Crit Care Med. 2000;161: 1037-46.

2. Canil K, Fitzgerald P, Lau G. Massive chylothorax associated with lymphangiomatosis of the bone. J Pediatr Surg. 1994;29:1186-8.

3. Takahashi K, Takahashi H, Maeda K, Homma S, Uekusa T, Dambara T, et al. An adult case of lymphangiomatosis of the mediastinum, pulmonary interstitium and retroperitoneum complicated by chronic disseminated intravascular coagulation. Eur Respir J. 1995;8:1799-802.

4. Zisis C, Rontogianni D, Charalambous E, Bellenis I. Lymphangiomatous hamartoma: cause or bystander of the isolated chylopericardium? J Thorac Cardiovasc Surg. 2005;130:1201-2.

5. Rostom AY. Treatment of thoracic lymphangiomatosis. Arch Dis Child. 2000;83:138-9.

\title{
Giant cavernous hemangioma of the distal esophagus treated with esophagectomy
}

\author{
Anthony W. Kim, MD, Robert J. Korst, MD, Jeffrey L. Port, MD, Nasser K. Altorki, MD, and Paul C. Lee, MD, New York, NY
}

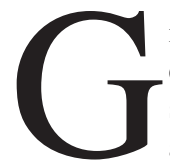
iant cavernous hemangiomas are rare tumors of the esophagus. In 1976, Feist, Talley, and $\mathrm{Hunt}^{1}$ described an upper esophageal hemangioma as "giant"; it was preoperatively $4 \times 7 \mathrm{~cm}$ and pathologically $12.0 \times 5.0 \times 2.5 \mathrm{~cm}$ in size. We present the case of an asymptomatic 68-year-old woman who had a giant hemangioma of the distal esophagus. She underwent an esophagectomy with

From the Department Cardiothoracic Surgery, Weill Medical College of Cornell University, New York, NY.

Received for publication Jan 16, 2007; accepted for publication Feb 12, 2007.

Address for reprints: Anthony W. Kim, MD, Rush University Medical Center, 1725 W Harrison St, Suite 774, Chicago, IL 60612 (E-mail: Anthony_kim@rush.edu).

J Thorac Cardiovasc Surg 2007;133:1665-7

0022-5223/\$32.00

Copyright $\odot 2007$ by The American Association for Thoracic Surgery doi:10.1016/j.jtcvs.2007.02.004 a gastric pull-up via a left thoracotomy. Her recovery was unremarkable and she is doing well at 4 months' follow-up.

\section{Clinical Summary}

A 68-year-old asymptomatic woman was found to have an abnormality on a chest radiograph before cataract surgery. A follow-up computed tomographic (CT) scan demonstrated a large lobulated distal esophageal mass with multiple small calcifications (Figure 1). Endoscopy was negative for mucosal lesion. A positron emission tomographic (PET) scan revealed that the mass had a standardized uptake value of 2.0. A transthoracic biopsy of the lesion demonstrated only blood and fibrinated material. Magnetic resonance imaging (MRI) reidentified the lobulated soft tissue mass in the distal esophagus and described it as a fusiform lesion involving the esophageal wall, causing narrowing of the lumen. Neither mediastinal invasion nor lymphadenopathy was noted. On the basis of the soft tissue signal and the smooth appearance, the lesion was thought to be a large leiomyoma.

The patient was brought to the operating room where she underwent a left posterolateral thoracotomy through the sixth 